Prozesse können hingegen nicht überzeugend für die breitere Öffentlichkeit symbolisiert werden. Die Forschung über politische Rituale und Symbole muss zudem sinnvollerweise mit Themen der institutionellen Legitimität verbunden werden. Müller beschäftigt sich abschließend mit Abgeordneteneiden, die sie als liturgischen Akt definiert. Sie verweist mit dieser Begriffsprägung auf die Antike, in der die Liturgie als Form des öffentlichen Dienstes galt, und definiert parlamentarische Liturgien als zeremonielle Prozesse, die der Sichtbarkeit in der Öffentlichkeit und der Bedeutungsübermittlung dienen. Sie unterscheidet als Hauptfunktionen der Eide die zeremonielle Symbolisierung des Mandatsbeginns und den materiellen Test der Verfassungskonformität der Abgeordneten. Ferner können die Eide Müller zufolge danach differenziert werden, ob sie religiös oder weltlich und militärisch oder zivilbürgerlich geleistet werden.

Insgesamt besticht der Band durch seine vielfältigen Einblicke in Rituale, Zeremonien, aber auch Routinen in verschiedenen Parlamenten. Die Auswahl der Fallbeispiele ist gelungen, da nicht nur Nationalparlamente untersucht werden. Es finden sich interessante Details und bedenkenswerte Interpretationen und Gedanken. In dieser Hinsicht erfüllt die Publikation den selbst gesetzten Anspruch. Wer mehr definitorische Klarheit erhofft, wird hier aber nicht fündig. Die Ausgangsfrage nach der Bedeutung der Rituale wird unterschiedlich beantwortet; ein gewisses Maß an Wichtigkeit sprechen ihnen alle Beitragenden zu, am weitesten geht Patzelt. Ein Resümee, das die verschiedenen Zugänge, Interpretationen und empirischen Informationen zusammenbindet und diskutiert, fehlt leider. So bleibt Patzelts Mahnung, nicht bei interessanten Ergebnissen stehenzubleiben. Der Band leistet aber eine wichtige Basis für zukünftig hoffentlich noch folgende theoriegeleitete Vergleiche.

Franziska Höpcke

\title{
Demokratische Repräsentation mit monarchischer Geschichte
}

\section{Manow, Philip: Im Schatten des Königs. Die politische Anatomie demokratischer Repräsenta- tion, Suhrkamp Verlag, Frankfurt am Main 2008, 170 Seiten, € 10,-.}

Moderne Demokratien verzichten gemeinhin auf üppig repräsentative Ornamente und übermäßig erhabene Selbstdarstellungsrituale. Während sich in früheren Jahrhunderten Monarchien in Form großer Paläste, Schlösser und Hofzeremoniell in Szene setzten, kommen demokratisch verfasste Staaten weitgehend ohne ausladende Repräsentationsgesten aus. In repräsentativen Demokratien findet das Prinzip der Volksherrschaft seinen sichtbaren Ausdruck im gewählten und damit demokratisch direkt legitimierten Parlament. Dennoch haben sich bestimmte Herrschaftsmerkmale aus der Zeit überkommener Monarchien - so argumentiert Philip Manow - bis in unsere Tage gehalten, die auch in modernen Demokratien fortleben. Damit sind demokratische Staaten nicht „nach-metaphysisch“ (S. 12), sondern in vielen Bereichen dauerhaft durch tradierte „Erinnerungsspuren“ (S. 10) überschichtet. So bilden heutige Demokratien letztlich keine vollständig durchrationalisierte, jeglichen zeremoniellen Pomps entkleidete Regierungsform; vielmehr ist auch in ihnen ein historisch eingeschliffenes Sediment vorhanden, das Zeichen alter Ordnungen bis in die Gegenwart erkennen lässt. Dieses Erbe früherer Herrschaftsformen nimmt Manow zum 
Ausgangspunkt seiner Untersuchung und zeigt, wie sehr demokratische Staatswesen auch heute noch durch monarchische Repräsentationsformen geprägt sind.

Während sich in absolutistischen Regimen die Herrschaft des Königs durch Hofstaat und Zeremonienkult manifestierte, kennt das demokratische Regierungssystem keine Kurzformel der symbolischen Machtrepräsentation. Das Parlament als Herzstück demokratischen Regierens scheint nicht in der Lage, einen prägnanten Ausdruck der Volkssouveränität hervorzubringen. Parlamentarische Sitzordnungen lassen sich nicht ausschließlich durch funktional-technische Erwägungen erklären, sondern spiegeln zu einem Gutteil „weiter zurückliegende Legitimationstraditionen“ (S. 35) wider. Sitzanordnungen in parlamentarischen Versammlungen symbolisieren die Vorstellung vom politischen Körper. Mit der Hinrichtung Louis XIV. in Frankreich war der Königskörper buchstäblich obsolet geworden. Als Folge der abgesetzten monarchischen Ordnung trat das Parlament an die Stelle, und die Versammlung „war nun selbst der neue geheiligte politische Körper“ (S. 47).

Manow untersucht vier zentrale parlamentarische Strukturmerkmale, die jeweils ausdrücken, wie stark auch heute noch vor-demokratische Prinzipien fortleben: parlamentarische Immunität, Publizität, Proportionalität und Diskontinuität. Die Abschaffung der Monarchie ging erstens einher mit der Souveränitätsübertragung vom König auf das Volk. Die Herausbildung repräsentativ-demokratischer Herrschaftsordnungen führte zu einer Übertragung eben jener Souveränität auf die Vertreter des Volkes. Der Immunitätsstatus der Parlamentarier macht die Abgeordneten gleichsam unantastbar wie zuvor den König und gibt ihnen eine heilige Aura als Stellvertreter des Demos. Die Öffentlichkeit parlamentarischer Diskussions- und Entscheidungspraxis gehört zweitens heute zum unabdingbaren Funktionsgebot jedes parlamentarischen Regierungssystems, doch die Schaffung von Publizität und Transparenz hat sich erst im Gefolge der Entzauberung der „mysteries of state“ (S. 78) durchgesetzt. Zuvor hatte lediglich der König Einblick in die Staatsgeschäfte; doch kaum war dieser abgesetzt, konnte die Einberufung der ersten Generalstände 1789 in Frankreich als Transmissionsriemen zur Herstellung (vor-)parlamentarischer Öffentlichkeit wirken. Im Gefolge des Übergangs von absolutistischen zu demokratischen Regierungsformen entwickelte sich drittens das Idealbild einer Strukturgleichheit zwischen Parlament und Volk. Die Übertragung der Souveränitätsrechte vom Königs- auf den Volkskörper sollte sich in der Zusammensetzung der gewählten Volksvertretung widerspiegeln. Damit war die Vorstellung vom Parlament als "gesellschaftlicher Mikrokosmos“ (S. 91) weniger ein Ausfluss der unmittelbar absolutistischen Ordnung, aber immerhin noch eine direkte Folge ihrer Abschaffung. Viertens steht heute das Prinzip parlamentarischer Diskontinuität als Surrogat für das natürliche Ableben des Königs. Wenn am Ende einer Wahlperiode alle sich noch in Beratung befindenden Gesetzesvorlagen nicht mehr erledigt werden, dann fallen sie dem „zivilen Tod des Parlaments“ (S. 101) zum Opfer. Die regelmäßige Wahl der Volksvertreter führt zu einer demokratisch legitimierten Neuerschaffung des Parlaments. Sie markiert nicht nur „die zivilisierte Hinrichtung des politischen Körpers“ (S. 104), sondern sichert auch die Unterbrechung sämtlicher Gesetzgebungstätigkeit, die einen symbolischen Wert an sich besitzt und sich aus funktionalen Erfordernissen heraus kaum begründen lässt.

Mit der Beseitigung des Ancien régime in Frankreich gegen Ende des 18. Jahrhunderts wurden parlamentarische Versammlungen einberufen, die das Prinzip der Volksherrschaft begründeten. Trotz dieser neu entstehenden Herrschaftsform lebten die alten Begriffe, die noch ganz dem Körper des Königs verhaftet waren, fort; und auf diese Weise wurde auch 
der nun ins politische Zentrum drängende Volkskörper noch mit den Begriffen der alten Ordnung beschrieben. Zwar markiert die umfassende Parlamentarisierung den Übergang von der persönlichen Herrschaft des Monarchen hin zu einer „entkörperlichten Souveränität des Volkes“ (S. 118), die dominanten überkommen geglaubten „Symbolordnungen“ (ebenda) besitzen jedoch noch eine starke Strahlkraft bis weit in die Neuzeit hinein. Auch in modernen aufgeklärten Demokratien wirken die Vorstellungswelten sowie die geistigen Landkarten des Ancien régime in parlamentarischen Verfahren und politischen Alltagspraktiken fort. Bis in unsere Tage werfen die „Symbolelemente der körperlichen Identitätsrepräsentation" (S. 139) ihre langen Schatten. So gibt es ein leicht mobilisierbares öffentliches Interesse am Staatsoberhaupt, das sich nicht lediglich auf seine Person bezieht, sondern auf seinen Körper. Dieser Fixierung auf den Herrschaftskörper ist es geschuldet, dass zum Beispiel das Stolpern von US-Präsident George W. Bush plötzlich zu einer Schlagzeile avanciert. Oberflächlich betrachtet mag dieses Interesse Ausdruck übersteigerter Neugierde sein, doch ist es eher - so Manow - das Spiegelbild der Verletzlichkeit und der Zerbrechlichkeit des unerschütterlich geglaubten Herrschers. Dem demokratischen Regierungsprinzip mit seinen durch Wahlen legitimierten Regierungsabfolgen ist eine „artificial eternity“ (S. 121) eingeschrieben, der Herrscherkörper ist aber auch heute noch den Gefahren von Schwäche und Verwundbarkeit ausgesetzt.

Mit seinem sehr dicht geschriebenen Buch vermag Philip Manow überzeugend zu zeigen, dass zeitgenössische Formen politischer Repräsentation nicht vollständig entpersonalisiert, sondern auch heute noch der Wirkmächtigkeit vergangener Ordnungen unterworfen sind. Die weit verbreitete Ansicht, dass politische Herrschaft heutzutage rein nach-metaphysisch sei, ist in Manows abschließendem Urteil „ein Irrtum einer Demokratietheorie, die sich die ganze Politik in Diskursen verflüssigt wünscht“ (S. 143).

Helge F. Jani

\section{Souveränitätsschimäre}

Mäder, Werner: Vom Wesen der Souveränität. Ein deutsches und europäisches Problem, Duncker \& Humblot (Beiträge zur Politischen Wissenschaft, Band 145), Berlin 2007, 198 Seiten, $€ 52$,-.

„Auf der Traditionslinie des ,klassischen’ Souveränitätsbegriffs liegt die ,Staatssouveränität', d.h. die Auffassung, dass das Wesensmerkmal des Staates die Souveränität sei. Ohne Souveränität kein Staat." (S.19) Für Werner Mäder, der nicht Größe und Bevölkerung der Staaten unterscheidet, „ist Macht das Wesensmerkmal von Souveränität. Die Macht ist Wirklichkeit" (S. 49). So gleitet der leitende Senatsrat a.D. von Jean Bodin über Thomas Hobbes, Friedrich Hegel, Carl Schmitt und Hermann Heller durch die Zeit und kommt in der Gegenwart nicht an. Kein Problem löst er mit den klassisch genannten Begriffen. Obwohl er oft Paul Kirchhof oder Josef Isensee zitiert, viele Rechtswissenschaftler nennt, Seiten mit Fußnoten füllt, bleibt sein Werk ein rechtspolitisches Traktat.

In der politischen Elite herrscht für Mäder eine Mentalität der Problemverdrängung mit seltsamer Richtungslosigkeit. Universalismen und Worthülsen wie „grenzenlose Demokra- 